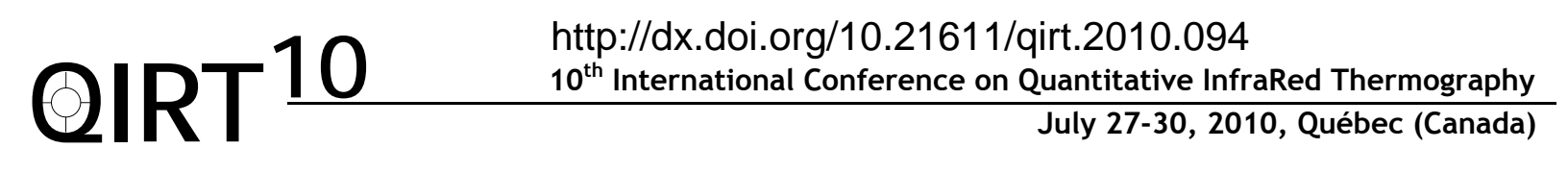

\title{
The influence of carbon dioxide on dynamic thermography results
}

by M. Moderhak* and M. Bajorek**

* Department of Biomedical Engineering, Gdansk University of Technology, Poland, matmod@biomed.eti.pg.gda.pl

** Department of Biomedical Engineering, Gdansk University of Technology, Poland, martom@biomed.eti.pg.gda.pl

\section{Abstract}

This paper presents the assessment of the influence of the $\mathrm{CO}_{2}$ cooling on active dynamic thermography (ADT) and thermal tomography (TT) results. This influence is great enough that one should consider taking it into account while thermal or dynamic parameters estimation. We try to estimate how much the infrared radiation is attenuated by the cloud of the $\mathrm{CO}_{2}$ gas present in front of the IR camera lens.

\section{Introduction}

There are different types of excitation in ADT or TT. We can distinguish from heating or cooling of the examined object Heating can be achieved by halogen lamps [1], microwave [2], ultrasound [3], etc.. Cooling can be performed by applying stream of cold air [4], cold water, ice, vaporous fluids [5] or as in our application the stream of $\mathrm{CO}_{2}$ [6]. In biomedical applications cooling has its special role. It causes body physiological reaction to cold which can be analysed to get diagnostic information. Moreover, it doesn't cause pain or discomfort, unlike heating, while e.g.: burn depth estimation.

\section{Problem statement}

It turns out that the stream of $\mathrm{CO}_{2}$ disturbs thermal transients recorded shortly after cooling stops. On figure $1 \mathrm{a}$ there is an example of such distortion. An unnatural fast grow in temperature return process is caused by the presence of the gas which did not left the space over measured area. This is well illustrated by the differential temperature of consecutive measurements (figure $1 \mathrm{~b}$ ).

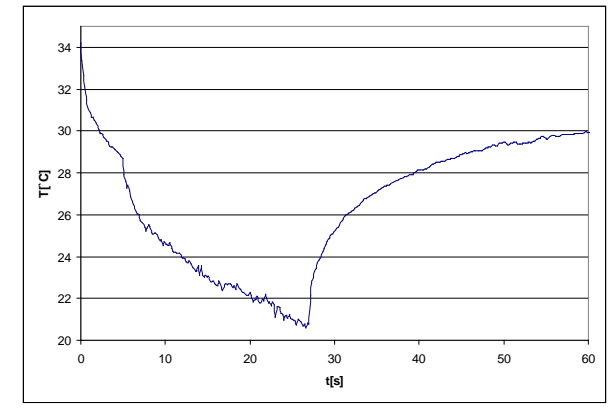

a.

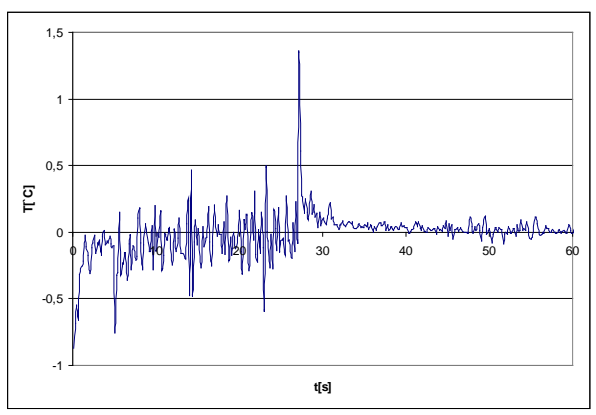

b.

Fig. 1a. Thermal transient during cooling and temperature return phase; $\boldsymbol{b}$. Differential temperature plot; maxima peak represents unnaturally fast temperature rise

\section{Results}

We experimentally estimated the influence of $\mathrm{CO}_{2}$ on temperature results. We used: Flir A320G thermal camera to measure temperature in selected region of interest, Fluke 9410 thermal calibrator as the radiation source and CryoT cryotherapy unit as the source of $\mathrm{CO}_{2}$. Measurements were taken with and without $\mathrm{CO}_{2}$ in front of the camera in order to calculate temperature change caused by the presence of the gas. Experimental setup is shown on figure 2 . 


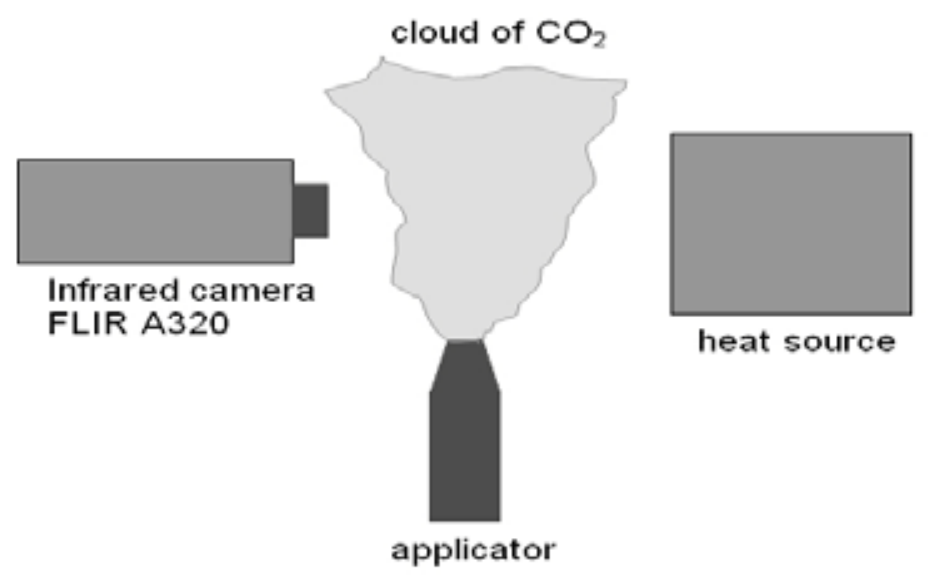

Fig. 2. The measurement set

The results of the work quantify the influence of $\mathrm{CO}_{2}$ gas on temperature measurement. Clear 'temperature damping' is measurable in the first moments after cooling shutdown. This leads to erroneous thermal or dynamic parameters estimation. To avoid false results we must be aware of time duration and scale of this phenomenon.

Acknowledgements: This research work was supported by the European Union in the framework of the European Social F und. The system project of the Pomorskie Voivodeship "InnoDoktorant - Scholarships for PhD students, II edition.

\section{REFERENCES}

[1] M. Kaczmarek, J . Rumiński, A. Nowakowski1, A. Renkielska, J. Grudziński, W. Stojek, "E valuation of new diagnostic procedures of medical thermography - in-vivo experiments", Dubrovnik , September,2002

[2] G. Cuccurullo, P. G. Berardi, R. Carfagna, V. Pierro, IR temperature measurements in microwave heating, Infrared Physics \& Technology 43, p. 145-150, 2002.

[3] A. Gleiter, C. S pießberger, G. Busse, "Lockin-thermography with optical or ultrasound", The 10th International Conference of the Slovenian Society for Non-Destructive, Ljubljana, Slovenia, p. 447-454, September 2009

[4] N. Arora, D. Martins, D. Ruggerio, E. Tousimis, A. J . S wistel, M. P. Osborne, R. M. Simmons, Effectiveness of a noninvasive digital infrared thermal imaging system in the detection of breast cancer, The American J ournal of Surgery 196, 523-526, 2008.

[5] M.Kaczmarek, "Thermal imaging and modelling of burned skin", 9th International Conference on Quantitative InfraRed Thermography J uly, 2008, Krakow - Poland

[6] E. Francis J. Ring, R. Vardasca, U. Bajwa, Monitoring Cooling Agents Applied to the skin of Normal Subjects by Quantitative Thermal Imaging, QIRT 2008 Conference Proceedings, p. 129-134, 2008. 